\title{
Relationships of open-field behaviour with anxiety in the elevated zero-maze test: Focus on freezing and grooming
}

\author{
Sira Díaz-Morán ${ }^{1}$, Celio Estanislau ${ }^{2}$, Toni Cañete ${ }^{1}$, Gloria Blázquez ${ }^{1}$, Andrea Ráez ${ }^{1}$, Adolf Tobeña ${ }^{1}$, \\ Albert Fernández-Teruel $^{{ }^{*}}$ \\ ${ }^{1}$ Medical Psychology Unit, Department of Psychiatry \& Forensic Medicine, Institute of Neurosciences, School of Medicine, Auto- \\ nomous University of Barcelona, Barcelona, España \\ ${ }^{2}$ Grupo de Pesquisa em Psicobiologia, Departamento de Psicologia Geral e Análise do Comportamento, Universidade Estadual de \\ Londrina, Londrina, Brazil \\ Email: *albert.fernandez.teruel@uab.es
}

Received 1 October 2013; revised 1 November 2013; accepted 7 November 2013

Copyright (C 2014 Sira Díaz-Morán et al. This is an open access article distributed under the Creative Commons Attribution License, which permits unrestricted use, distribution, and reproduction in any medium, provided the original work is properly cited. In accordance of the Creative Commons Attribution License all Copyrights (C) 2014 are reserved for SCIRP and the owner of the intellectual property Sira Díaz-Morán et al. All Copyright @ 2014 are guarded by law and by SCIRP as a guardian.

\section{ABSTRACT}

The National Institutes of Health Genetically Heterogeneous Rat Stock (NIH-HS) is a unique tool for genetic studies of complex traits due to its high genetic heterogeneity and to its high level of genetic recombinants accumulated along many outbreeding generations. In the present study, 90 NIH-HS male rats were tested for anxiety/fearfulness in the elevated zero-maze and in the open-field test in order to investigate the associations among defensive responses from both tests and, in particular, those among openfield self-grooming and freezing. These associations were evaluated by means of a correlational-factorial approach and an analysis of differences between subgroups displaying extreme scores in representative variables. The final factor analysis revealed a first factor with high loadings of all variables from the zero-maze ("Maze timidity/conflict" factor), and a second (independent) factor dominated by open-field crossings $(-0.74)$, rearings $(-0.62)$ and freezing $(0.65)$, with lower loadings of open-field grooming $(-0.39)$ and stretched attend postures, as well as of entries and time (loadings of -0.32 to -0.25 ) in the open sections of the zero-maze ("Open Behavior inhibition/ desinhibition” factor), suggesting that open-field selfgrooming is a response associated to activity, in the present study, rather than to inhibition. Furthermore, the finding that grooming in the OF loaded negatively in a second factor supports a relationship between grooming and dearousal. Present results, thus, are in accordance with the usefulness of these tests for the purposes they are commonly employed and add new ${ }^{*}$ Corresponding author. evidence supporting their concurrent validity, as indicated by the relationships observed among measures from both tests.

\section{KEYWORDS}

Genetically Heterogeneous NIH-HS Stock; Elevated Zero-Maze; Open-Field; Freezing; Grooming

\section{INTRODUCTION}

The genetically heterogeneous NIH-HS rat stock ("National Institutes of Health Genetically Heterogeneous Rat Stock”) was developed by Hansen and Spuhler [1] with the aim of having a more naturalistic rat type (as compared with the usual laboratory rat strains at that time), which could yield a broad-range distribution of responses to experimental conditions and could serve as a base population for selection studies. So, with the goal of optimizing the distribution of genotypic frequencies and recombination within the laboratory rat population, the NIH-HS rat stock was formed through an eight-way cross of as much as possible separate inbred strains which were readily available. These eight parental strains were: the $\mathrm{MR} / \mathrm{N}, \mathrm{WN} / \mathrm{N}$ and $\mathrm{WKY} / \mathrm{N}$ (these three strains trace their ancestry to the original Wistar stock); the M520/N and F344/N (both established in the 1920s, but of unknown origin); the ACI/N (hybrid between the August and Copenhagen strains), the BN/SsN (derived from a colour mutant from a stock of wild rats kept at the Wistar Institute) and the BUF/N strain [1,2].

The phenotypes showed by these NIH-HS rats in up to 16 ethanol-related traits lend initial support to the effectiveness of the program, as for all traits except one the 
values of the heterogeneous stock were within the high and low values of the eight founder inbred strains [1,2].

In our laboratory we have conducted extensive studies for the characterization of NIH-HS regarding their anxiety/fearfulness defensive profiles, as well as with regard to their stress hormone and "depressive-like" responses [3-11]. Collectively, the results from all these studies have revealed that the NIH-HS rat stock presents a behavioral/endocrine profile which fits well with one of a rather timid, anxious, passive (reactive) coper, stressprone and "despair-prone" rat.

Besides that, the multitest battery used across the above mentioned studies, comprising a series of unconditioned anxiety/fearfulness tests (novelty-induced exploratory activity, the light/dark box, the elevated zeromaze, the baseline acoustic startle response) as well as several conditioned fear or anxiety tests/tasks (the fearpotentiated startle, context-conditioned freezing, the acquisition of two-way active avoidance in a shuttle box), enabled us to achieve relevant conclusions concerning (i) what is measured by different (unconditioned and conditioned) anxiety/fear tests, and (ii) how different anxiety and fear responses are associated to each other to the point of forming dimensions or traits (see [4,5,7-9]).

However, NIH-HS rats have not yet been evaluated in the open-field test, which is one of the most typical and traditional tests of fearfulness [12-20]. Its common use across most behavioural neuroscience laboratories makes it relevant to know how NIH-HS rats behave in the open field test. Besides the evaluation of horizontal/vertical exploratory activity and freezing behavior, the open field test also allows the study of self-grooming behavior, which is often interpreted as a fearfulness/anxiety-related behavior [15,21-24], although as we will see below such an interpretation is still very controversial.

In fact, it is commonly assumed that in rats exposed to novelty for short periods (e.g. testing in novel cages/ environments, in the open field test, in the hole-board test, etc), which usually last for only 5 - 10 minutes, the amount of self-grooming behaviour is an index of their fearfulness/anxiety or perceived stress levels. In support of that contention, experimental evidence shows, for instance: (i) The Roman High-avoidance (RHA) and Roman Low-Avoidance (RLA) rat lines/strains are relatively low and high anxious/fearful, respectively. In agreement with the above-mentioned contention that self-grooming represents anxiety/fear levels, RHAs display much less self-grooming than RLA rats when exposed to a variety of anxiety/fearfulness tests involving novelty, such as novel cage/timidity tests, different types of open-field tests, the elevated plus-maze test, the holeboard test, and others $[15,24,25]$. (ii) Likewise, in a F2 generation of rats (derived from the RHA-I and RLA-I strains; [21] self-grooming has been shown to be posi- tively associated with other anxiety-related variables (see $[21,22])$ in factor analytical studies of various unconditioned and conditioned anxiety/fearfulness tests in a very large rat sample ( $\mathrm{n}=800$ F2 rats; [21,22]). (iii) Selfgrooming behaviour in rats is increased through the manipulation of stress intensities, as well as by administration of some stress-inducing agents (for a review, see [26]). (iv) Most outstandingly, tail-pinch stress, as well as the administration of the anxiogenic (GABAergic) drugs ZK 93426 and pentylenetetrazol induced fear-related behaviors and a parallel increase in self-grooming only in RLA rats (high-anxious) but not in the RHA rat line [27]. (v) Of similar relevance was the finding that novelty-induced self-grooming behaviour of RLA rats can be long-lastingly reduced neonatal handling, a treatment that is known for its enduring anti-anxiety and antistress behavioral and neurobiological effects [24].

Despite the evidence in favour of self-grooming as an index of fearfulness/anxiety, most of the works devoted to investigate anxiety or novelty-induced behavior do not consider grooming as a target variable. That could be due, at least partly, to the fact that some influential works carried out in order to identify the dimensions of the rat exploratory behavior do not attribute to grooming the status as an anxiety measure, in contrast to what $[21,22]$ or Steimer et al. $[23,24]$ have suggested. For example, there have been reports on factor analyses (e.g. [28,29]) of elevated plus maze variables/responses in which selfgrooming loaded nearly isolated in a fourth or sixth factor (respectively), apart from an "anxiety factor", and was tentatively interpreted as "conflict" or "displaced activity". In addition, in their review on the utility of the open field test in evaluating the effects of drugs on anxiety-like behaviors, [30] reported contradictory findings concerning drug effects on open field-induced self-grooming: while some anxiolytics increased grooming activity, both anxiolytic and anxiogenic agents were reported to decrease it.

Besides studying the within-test associations (among variables from a given test), it is especially interesting and scientifically important to evaluate the relationships of open field responses, including freezing and selfgrooming, with anxiety-related variables from other tests (e.g. is self-grooming or freezing in the open-field test related/associated with an anxiety variable measured in a different test?), as this "across test" approach can strengthen (or weaken) the validity of a given response or variable. This "across test" approach has been seldomly used, with some exception as ([21,22]; see review by Lopez-Aumatell et al. [9]). In fact, Aguilar et al. [21,22] used a multi-test approach (a battery of seven unconditioned and conditioned tests/tasks of anxiety/fearfulness) in a very large F2 rat sample and obtained evidence that self-grooming in the open field was associated with an- 
xiety-related variables from several other (unconditioned and conditioned) anxiety tests. Although such associations were mostly in the hypothetically-expected direction (e.g. the shorter the self-grooming duration in the open field test the lower the levels of anxiety in the shuttle box avoidance task), they were not very strong according to the relatively low factorial loadings $[21,22]$. Thus the need to address this issue in NIH-HS rats by using the elevated zero-maze test of anxiety as a tool of external or concurrent validity to study associations with open-field test variables.

Thus, according to the anxious/fearful and passive coping profiles which characterize them (see above), we expected NIH-HS rats to display substantial grooming responses during open-field exposure (we expected values in the range of the typical scores of RLA rats, which usually spend between 40 - 60 s self-grooming in 5-min novelty tests, significantly longer than their RHA counterparts; see for instance $[15,31,24])$. Due to the high genetic heterogeneity and to the high level of genetic recombinants accumulated along many outbreeding generations (making the NIH-HS stock a unique tool for genetic studies of complex traits; (e.g. [3,6]) we expected that testing NIH-HS rats in the elevated zero-maze and the open-field tests would bring further relevant information on their behavioural defensive profile, as well as on the relationships among variables from both tests, including the associations of self-grooming and freezing with other behaviors. For the above reasons it is to be expected that the behavioural results obtained with these rats should be more generalizable than those obtained by using any other particular rat strain.

\section{MATERIAL AND METHODS}

\subsection{Animals}

Ninety adult male NIH-HS rats ("National Institutes of Health Genetically Heterogeneous Rat Stock” [1]), from our permanent colony of 40 families, were used. The progenitors of our NIH-HS rat colony were kindly provided by Dr. Eva Redei in 2004 (Center for Comparative Medicine, Northwestern University, Chicago, USA) [7]. The original heterogeneous rat stock was derived from an eight-way cross of the following 8 inbred strains: the MR/N (Maudsley Reactive), WN/N (Wistar Nettleship) and WKY/N (Wistar Kyoto; these three strains trace their ancestry to the original Wistar stock); the M520/N and F344/N (Fischer 344; both strains established in the 1920s, but of unknown origin); the ACI/N (Agouti; hybrid between the August and Copenhagen strains), the BN/SsN (Brown Norway; derived from a color mutant from a stock of wild rats kept at the Wistar Institute) and the BUF/N (Buffalo) strain [1].

Subjects were approximately 3.5 months old at the beginning of the experiment (weight: $291.24 \pm 4$.6; mean \pm sem). They were housed in pairs in macrolon cages (50 $\mathrm{cm} \times 25 \mathrm{~cm} \times 14 \mathrm{~cm}$ ), maintained with food and tap water available ad libitum, under conditions of controlled temperature $\left(22^{\circ} \mathrm{C} \pm 2^{\circ} \mathrm{C} ; 50 \%-70 \%\right.$ humidity) and a 12-h light/12-h dark cycle (lights on at 08:00 h).

\subsection{Procedure and Apparatus}

Experiments were performed during the light cycle, between 09:00 and 14:00 h., and in accordance with the Spanish legislation on "Protection of Animals Used for Experimental and Other Scientific Purposes" and the European Communities Council Directive (86/609/EEC) on this subject. The experimental protocol was approved by the Autonomous University of Barcelona Ethics committee. Two behavioral tests were administered, i.e. the elevated zero-maze and the open-field tests. One week elapsed between both tests. The characteristics of the tests and procedure were as follows:

\subsubsection{Elevated Zero-Maze (ZM)}

The maze, similar to that described by Shepherd, Grewal, Fletcher, Bill \& Dourish (1994), comprised an annular platform (105 cm diameter; $10 \mathrm{~cm}$ width) made of black plywood and elevated to $65 \mathrm{~cm}$ above the ground level. It had two open sections (quadrants) and two enclosed ones (with walls $40 \mathrm{~cm}$ height). The subject was placed in an enclosed section facing the wall. The apparatus was situated in a black testing room, dimly illuminated with red fluorescent light, and the behavior was videotaped and measured outside the testing room. Latency to enter into an open section (Latency to open), time spent in the open sections (Time), number of entries in the open sections (Entries), number of stretched attend postures (SAP-ZM) and number of Head-dips (Head-dips) were measured for 5 minutes [7,8,32,33].

\subsubsection{Open-Field (OF)}

It consisted of a circular platform $(82.5 \mathrm{~cm}$ diameter) with $34 \mathrm{~cm}$ walls. The box floor was painted with black lines $(2 \mathrm{~mm})$ to form 19 equal sectors. The rat was placed at a peripheral sector in a position parallel to the wall. The test was carried out in the same room as the zero-maze test. However, the apparatus was illuminated by a white fluorescent (60 W) lamp. The number of crossings between sectors (Crossings), rearings (Rearings), stretched attend postures (SAP-OF) and the duration of freezing (Freezing) and grooming (Grooming) were measured for 5 minutes.

\subsection{Statistical Analysis}

A correlation matrix and an obliquely-rotated (oblimin direct) factor analysis were applied to study the associations among the 11 most relevant dependent variables (SPSS Windows, 17.0, SPSS Inc., USA). According to 
our previous works $[7,8]$ the next step was to reduce the initial obtained solution to a minimum and meaningful number of non test-related factors (Direct Oblimin method) following appropriate application of the Catell's Scree test (for more detailed justification of these factorial procedures see $[7,21]$ ). In addition, groups with extreme scores were formed (selecting subjects with variable scores of at least \pm one standard deviation; see descriptive statistics in Table 1) in the most important OF variables as well as “entries into open sections" in ZM test, and Student's t-tests for independent groups were applied to compare those extreme subgroups.

\section{RESULTS}

Table 1 indicates descriptive results of the whole sample of NIH-HS rats in behavioral measures of $\mathrm{ZM}$ and OF. They are quite comparable to those obtained in our previous studies with these rats tested in the ZM (e.g. [4,8]).

The correlation matrix (Table 2) mainly shows: 1) Moderate to high correlations within the ZM measuresHead-dips, entries, and time in the open sections showed high positive correlation whatever the pair analyzed. These measures were positively correlated with SAP-ZM and negatively correlated with the latency to enter anopen section. 2) Low to moderate correlations within the OF measures-Both crossings and grooming were found to be negatively correlated with freezing and SAP-OF and positively correlated with rearings. However, crossings and grooming were not reliably correlated. Rearings and SAP-OF were negatively correlated. 3) Low to moderate inter-tests correlations - Rearings in the OF were positively correlated with head-dips, entries, and time in the open sections of the ZM. Entries in the open sections of the ZM correlated with crossings in the OF. Head-dips in the ZM were positively correlated with grooming in the OF.

Obliquely-rotated factor analyses (direct oblimin) were then applied to the most relevant variables of the Elevated zero-maze and Open-field (Table 3(a)). A 5factor solution was obtained. Factor 1 seems to represent exploration in the ZM, since all the ZM variables (latency to open was the only which loaded negatively) loaded in that factor. Interestingly, rearings in the OF also loaded in Factor 1 . Factor 2 seems to mainly represent fearfulness in the OF, since freezing loaded highly in that factor, just like crossings (which loaded negatively). Rearings (negatively) in the OF and to a lesser extent SAP in the ZM, also contributed to this factor. Factor 3, which showed a heavy negative loading of SAP-OF, seems to represent an instance of exploratory behavior, since OF rearings and crossings loaded positively in this factor, while SAP-ZM loaded negatively. Grooming in the OF heavily loaded in Factor 4, which also showed moderate loadings from latency to open, SAPs and headdips in the ZM, rearings and freezing (negative loading) in the OF. As grooming is reported to be increased by novelty exposure [26], this factor seems to blend elements of investigatory behavior (SAP and head-dips in

Table 1. Descriptive statistics of behavioral responses from NIH-HS rats in the open-field and elevated zero-maze tests $(n=90)$.

\begin{tabular}{|c|c|c|c|c|c|}
\hline & paradigm & Mean & SD & SEM & RANGE \\
\hline \multirow{5}{*}{ Elevated zero maze } & Latency to open-ZM (s.) & 104.62 & 125.25 & 13.20 & $3-300.00$ \\
\hline & SAP-ZM (\#) & 6.03 & 3.49 & 0.37 & $0-14.00$ \\
\hline & Entries-ZM (\#) & 2.79 & 3.39 & 0.36 & $0-18.00$ \\
\hline & Time-ZM (s.) & 35.62 & 43.75 & 4.61 & $0-167.00$ \\
\hline & Head-dips-ZM (\#) & 3.37 & 4.100 & 0.43 & $0-22.00$ \\
\hline \multirow{5}{*}{ Open-Field } & Freezing-OF (s.) & 14.93 & 27.15 & 2.86 & $0-162.41$ \\
\hline & Grooming-OF (s.) & 61.88 & 46.75 & 4.98 & $0-191.00$ \\
\hline & Defecations-OF (\#) & 3.28 & 2.46 & 0.26 & $0-9.00$ \\
\hline & Rearings-OF (\#) & 9.47 & 7.57 & 0.80 & $0-40.00$ \\
\hline & Crossings-OF (\#) & 36.16 & 21.90 & 2.30 & $3-113.00$ \\
\hline
\end{tabular}

Means + SEM (and SD) of behavioral measures of the NIH-HS shown, $\mathrm{n}=90$. Latency to open: latency (s) to the first entry into a open section in the elevated Zero-maze. SAP-ZM: stretched attend postures in the elevated Zero-maze (\#). Entries: total number of the entries in the open sections (\#). Time: time spent (s) in the open sections. Head-dips: the animal places its head outside the corner of the open section in the elevated Zero-maze, to a minimum depth such that the ears were level with the floor of the apparatus (a new bout of head-dipping was recorded if the animal raised its head fully outside the corner of the open section before resuming). Freezing: total time of freezing (s) during five minutes. Grooming (s): grooming duration in the Open-field. Defecations (\#): number of defecations during Open-Field test. SAP-OF: stretched attend postures in tne Open-field (\#). Rearings: total number of the rearings during 5 minutes. Crossings (\#): number of square crossings during Open-Field test. 
Table 2. Correlation matrix among the main behavioral variables.

\begin{tabular}{|c|c|c|c|c|c|c|c|c|c|c|c|}
\hline & \multicolumn{6}{|c|}{ Open-field } & \multicolumn{5}{|c|}{ Zero-maze } \\
\hline & $\begin{array}{l}\text { Freezing } \\
\text { (s.) }\end{array}$ & $\begin{array}{l}\text { Grooming } \\
\text { (s.) }\end{array}$ & $\begin{array}{l}\text { Defecations } \\
\qquad(\#)\end{array}$ & $\begin{array}{l}\text { SAP-OF } \\
(\#)\end{array}$ & $\begin{array}{l}\text { Rearings } \\
(\#)\end{array}$ & $\begin{array}{l}\text { Crossings } \\
\qquad \#)\end{array}$ & $\begin{array}{c}\text { Latency to } \\
\text { open (s.) }\end{array}$ & $\begin{array}{c}\text { SAP-ZM } \\
(\#)\end{array}$ & $\begin{array}{c}\text { Entries } \\
(\#)\end{array}$ & $\begin{array}{l}\text { Time } \\
\text { (s.) }\end{array}$ & $\begin{array}{c}\text { Head-dip } \\
\text { s (\#) }\end{array}$ \\
\hline Freezing-OF (s.) & 1 & & & & & & & & & & \\
\hline Grooming-OF (s.) & $-0.248^{*}$ & 1 & & & & & & & & & \\
\hline Defecations-OF (\#) & 0.025 & -0.008 & 1 & & & & & & & & \\
\hline SAP-OF (\#) & -0.094 & $-0.260^{*}$ & -0.030 & 1 & & & & & & & \\
\hline Rearings-OF (\#) & -0.196 & $0.210^{*}$ & 0.177 & $-0.222^{*}$ & 1 & & & & & & \\
\hline Crossings-OF (\#) & $-0.464^{* *}$ & -0.054 & -0.019 & $-0.224^{*}$ & $0.226^{*}$ & 1 & & & & & \\
\hline Latency to open-ZM (s.) & 0.061 & 0.017 & 0.021 & 0.039 & -0.087 & -0.068 & 1 & & & & \\
\hline SAP-ZM (\#) & 0.030 & 0.133 & -0.010 & 0.098 & 0.014 & -0.139 & -0.185 & 1 & & & \\
\hline Entries-ZM (\#) & -0.176 & 0.144 & -0.156 & -0.083 & $0.233^{*}$ & $0.253^{*}$ & $-0.545^{* *}$ & $0.443^{* *}$ & 1 & & \\
\hline Time-ZM (s.) & -0.167 & 0.097 & -0.169 & -0.014 & $0.264^{*}$ & 0.162 & $-0.547^{* *}$ & $0.483^{* *}$ & $0.912^{* *}$ & 1 & \\
\hline Head-dips-ZM (\#) & -0.089 & $0.215^{*}$ & -0.130 & 0.002 & $0.410^{* *}$ & 0.048 & $-0.385^{* *}$ & $0.577^{* *}$ & $0.735^{* *}$ & $0.800^{* *}$ & 1 \\
\hline
\end{tabular}

Significant correlations are shown in bold. Latency to open: latency (s) to the first entry into a open section in the elevated Zero-maze. SAP-ZM: stretched attend postures in the elevated Zero-maze (\#). Entries: total number of the entries in the open sections (\#). Time: time spent (s) in the open sections. Head-dips: the animal places its head outside the corner of the open section in the elevated Zero-maze, to a minimum depth such that the ears were level with the floor of the apparatus (a new bout of head-dipping was recorded if the animal raised its head fully outside the corner of the open section before resuming). Freezing: total time of freezing (s) during five minutes. Grooming (s.): grooming duration in the Open-field test. Defecations (\#): number of defecations during Open-Field test. SAP-OF: stretched attend postures in the Open-field test (\#). Rearings: total number of the rearings during 5 minutes. Crossings (\#): number of square crossings during Open-Field test. ${ }^{*} \mathrm{p} \leq 0.05$ Pearson's correlation coefficient. ${ }^{* *} \mathrm{p} \leq 0.001$ Pearson's correlation coefficient; $\mathrm{n}=90$.

Tab le 3. Factor analyses for the NIH-HS rat sample (five- and two-factor solutions).

(a)

\begin{tabular}{|c|c|c|c|c|c|}
\hline A) First Oblimin direct factor analysis & Factor 1 & Factor 2 & Factor 3 & Factor 4 & Factor 5 \\
\hline \multicolumn{6}{|c|}{ Elevated zero-maze } \\
\hline Latency to open-ZM (s.) & -0.64 & - & - & 0.30 & - \\
\hline SAP-ZM (\#) & 0.61 & 0.27 & -0.34 & 0.36 & - \\
\hline Entries-ZM (\#) & 0.92 & - & - & - & - \\
\hline Time-ZM (s.) & 0.94 & - & - & - & - \\
\hline Head-dips-ZM (\#) & 0.88 & - & - & 0.32 & - \\
\hline \multicolumn{6}{|c|}{ Open-field } \\
\hline Freezing-OF (s) & - & 0.84 & - & -0.28 & - \\
\hline Grooming-OF (s.) & - & - & - & 0.87 & - \\
\hline Defecations-OF (\#) & - & - & - & - & 0.89 \\
\hline SAP-OF (\#) & - & - & -0.91 & - & - \\
\hline Rearings-OF (\#) & 0.32 & -0.34 & 0.33 & 0.30 & 0.60 \\
\hline Crossings-OF (\#) & - & -0.84 & 0.35 & - & - \\
\hline Eigenvalues & 3.55 & 1.71 & 1.28 & 1.07 & 1.04 \\
\hline Explained variance: 78.7\% & & & & & \\
\hline
\end{tabular}


(b)

\begin{tabular}{ccc}
\hline & Factor $\mathbf{~}$ & Factor 2 \\
\hline Suggested names & Maze timidity/conflict & Open Behavior inhibition/desinhibition \\
\hline Latency to open-ZM (s.) & Elevated zero-maze & - \\
SAP-ZM (\#) & -0.59 & - \\
Entries-ZM (\#) & 0.68 & -0.32 \\
Time-ZM (s.) & 0.89 & -0.25 \\
Head-dips-ZM (\#) & 0.92 & - \\
& 0.88 & 0.65 \\
Freezing-OF (s) & Open-field & -0.39 \\
Grooming-OF (s.) & - & - \\
Defecations-OF (\#) & - & 0.47 \\
SAP-OF (\#) & - & -0.62 \\
Rearings-OF (\#) & - & -0.74 \\
Crossings-OF (\#) & - &
\end{tabular}

Correlation between factors $=-0.074$.

Loadings $\geq 0.25$ are shown. (a) Direct oblimin five-factor solution with 11 selected variables (factors with eigenvalues greater than 1 ). (b) Two-factor solution and correlation between factors, showing that both factors are orthogonal (independent); $\mathrm{n}=90$.

the $\mathrm{ZM}$ and rearings in the $\mathrm{OF}$ ) with those of passive coping (latency to open in the ZM, grooming in the OF). The negative loading of freezing in OF may result from its incompatibility with grooming. Rearings and defecations in the OF loaded in Factor 5, thus coupling a response sometimes seem as fearful (defecation) with an exploratory behavior (rearing).

We aimed to obtain a minimum number of conceptually meaningful (and not so much test-related) factors, thus the first test-related 5-factor structure was reduced to two-factor solution after applying the Catell's Scree test (see "Eigenvalues" in Tables 3(a) and (b); see [7,21, 22], for application of the Catell's Scree test).

This solution (Direct Oblimin) showed two independent factors (correlation between factors $=-0.074$ ), with Factor 1 grouping anxiety variables frrom the elevated zero-maze test (loadings of -0.59 to 0.92 ; we called it “Maze timidity/conflict", to be consistent with our previous studies [7,8,11,21]. Factor 2 appears to represent the behavioral change that rats make when they stop doing freezing behavior and begin to engage in exploratory behavior and self-grooming, as indicated by the loadings of open-field test variables (loadings of -0.25 to -0.74 for SAP-OF, freezing, self-grooming, rearings and crossings), which are accompanied by loadings of elevated zero-maze variables (loadings of -0.25 to -0.32 for Entries and Time). We thus temptatively called Factor 2 as “Open Behavior inhibition/desinhibition” factor. It is especially interesting that self-grooming showed a loading of -0.39 , with the same sign than OF crossings
$(-0.74)$, OF rearings $(-0.62)$ or ZM “entries” $(-0.32)$, and opposite sign to freezing (0.65) (see Table 3(b)).

Finally, comparison between "low" (scores at least one standard deviation below the means) and "high" (score at least one standard deviation above the means) groups in respect to key variables (Figure 1) showed that: (a) "High grooming” duration group tended to spend less time freezing $(\mathrm{t}[25]=1.99, \mathrm{p}=0.029$, one-tailed $)$ and to show less SAPs $(\mathrm{t}[25]=2.03, \mathrm{p}=0.053)$ in the OF than the "low grooming" group (Figure 1(a)). (b) As compared to the "low freezing” group, the "high freezing” group (Figure 1(b)) was found to spend less time grooming, to perform less crossings in the OF, as well as decreased time and entries into the open sections of the ZM $(\mathrm{t}[25]>2.11$, $\mathrm{p}<0.05$; Figure 1(b)). (c) "High crossings" group (Figure 1(c)) presented less freezing and performed more rearings in the OF, as well as more entries into the open areas of the ZM than its "low crossings" counterpart (all t > 2.25, p < 0.05). (d) "High rearings" group performed more crossings and spent less time freezing in the OF, as well as decreased SAPs in the ZM as compared to the "low rearing” group (all t $>2.54, \mathrm{p}<0.05$; Figure 1 (d)). (e) The group showing "higher entries into the open sections" in the ZM spent more time in these areas and less time freezing in the OF (all $t>3.26, p<0.05$ ), while they also tended to perform more crossings in the OF $(\mathrm{t}[25]=1.76$, $\mathrm{p}=0.084$ ) than the "low entries" group (Figure $1(\mathrm{e})$ ).

\section{DISCUSSION}

Ninety genetically heterogeneous $\mathrm{NIH}-\mathrm{HS}$ male rats 


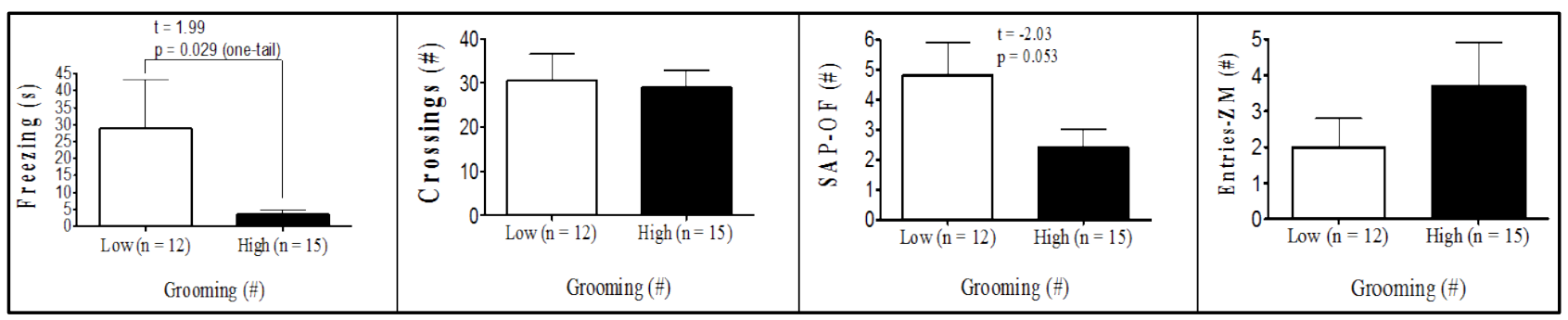

(a)

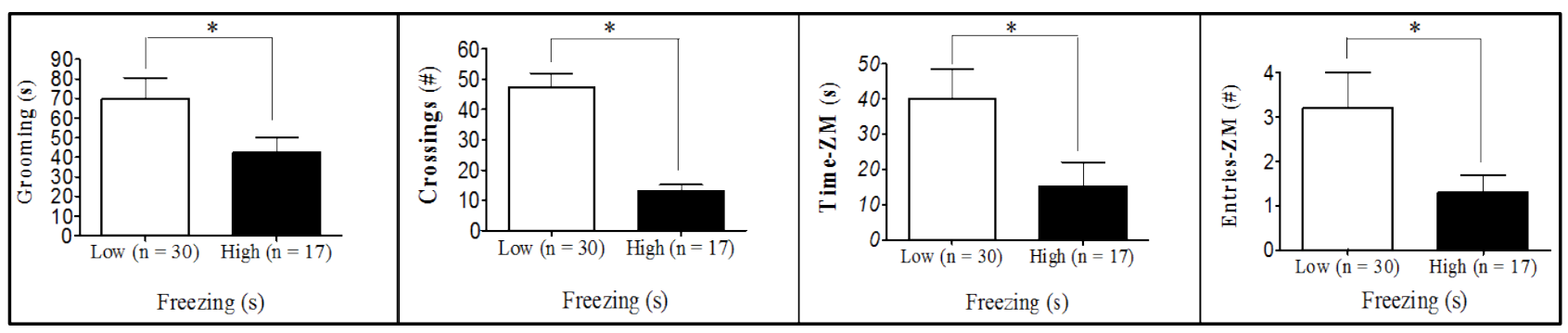

(b)

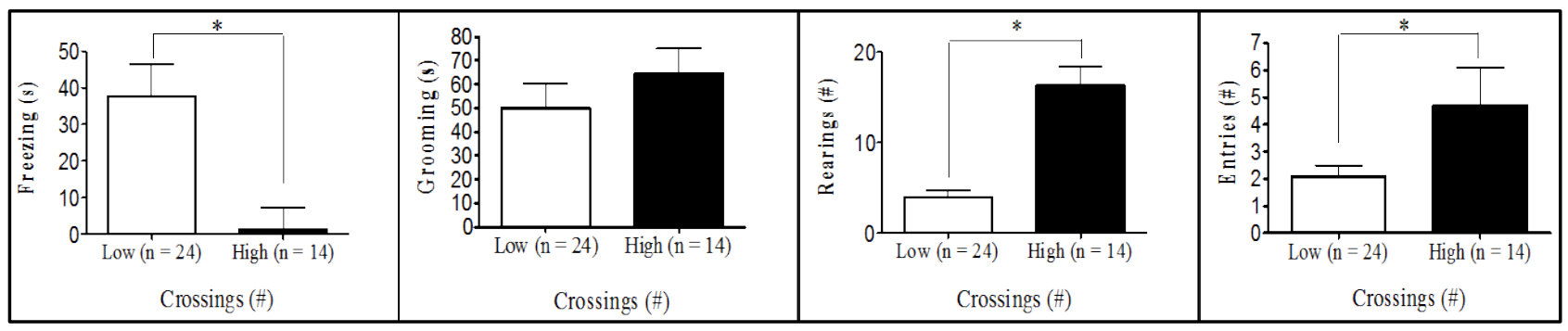

(c)

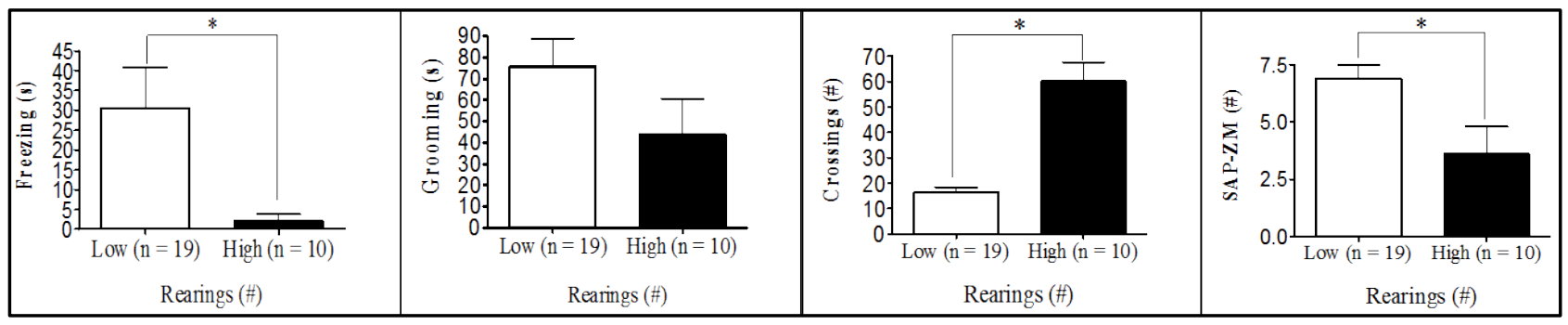

(d)

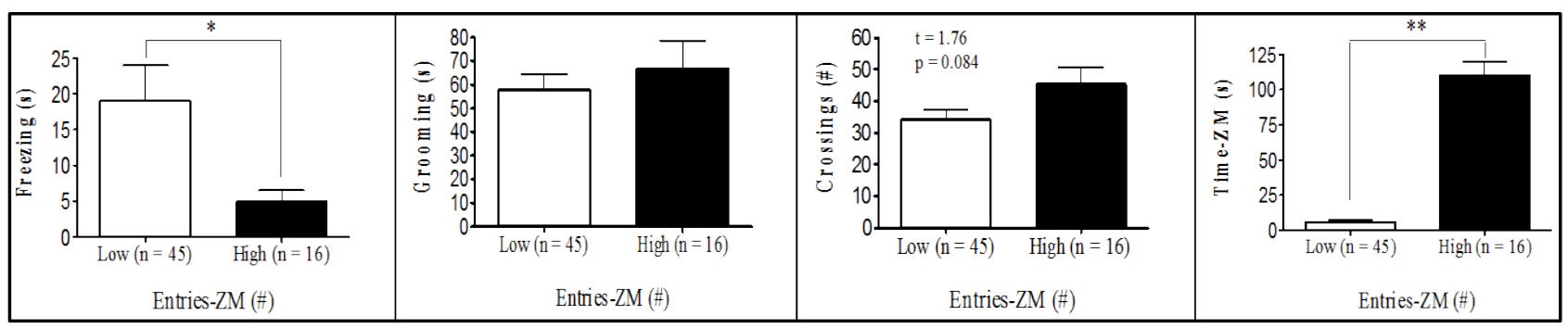

(e)

Figure 1. (a)-(e): Selection by extreme scores in self-grooming, freezing and some of the most relevant OF and $\mathrm{ZM}$ variables. ${ }^{*} \mathrm{p} \leq 0.05$ Student's t-test for independent samples; ${ }^{* *} \mathrm{p} \leq 0.001$ Student's t-test for independent samples.

were tested for anxiety and fearfulness in the elevated zero-maze and in the open-field test in order to investigate the associations among defensive responses from both tests and, in particular, those among open field self-grooming and freezing with other more typical (and well-validated) anxiety responses. The main findings of 
the present study can be summarized as follows: (i) First of all, NIH-HS rats, tested for the first time in the open field test, show substantial amount of behaviour of all types in this test (see means and ranges in Table 1). In particular, they show relevant levels of freezing, and a mean duration of self-grooming that is in the range, or even higher than that typically shown by the "high-anxious” RLA rats (in fact, Roman rats which were tested in the open field approximately during the same period of the present study showed grooming values of $47.9 \pm$ $5.9 \mathrm{~s}$, the RLA, and $11.3 \pm 2.4 \mathrm{~s}$, the RHA rats; $\mathrm{n}=$ 12/strain; data not shown; but see $[15,24,31])$. (ii) The final two-fold solution of factor analysis reveals a first factor with high loadings of all variables from the elevated zero-maze ("Maze timidity/conflict" factor), and a second orthogonal (independent) factor which is dominated by crossings, rearings and freezing, and with lower loadings of grooming, OF-SAP, ZM entries and ZM time (“Open Behavior inhibition/disinhibition" factor). It is especially remarkable that, in the second factor, selfgrooming showed a loading of -0.39 , with the same sign as crossings $(-0.74)$, rearings $(-0.62)$ or ZM "entries" $(-0.32)$, and opposite sign to freezing $(0.65)$. This suggests that OF self-grooming is a response associated to activity, in the present study, rather than to inhibition (see further discussion below). (iii) This contention is mostly confirmed by the comparisons between extreme subgroups (Figures 1(a)-(e)), as highlighted by the following summary of results: (a) The differences between the subgroups selected for extreme grooming scores in $\mathrm{OF}$ freezing (i.e. high groomers showed less freezing, $\mathrm{p}=$ 0.029 , see Figure 1(a)) as well as in SAP in the open field test (i.e. high groomers showed less SAP, $\mathrm{p}=0.053$, see Figure 1(a)). (b) The findings that higher levels of OF freezing (in comparison to the low freezing group) were associated with shorter OF grooming duration and lower number of OF crossings, as well as - and this is outstanding - with shorter ZM time in open sections and lower number of ZM entries (see Figure 1(b)). These results, relating freezing in the open field with ZM time and entries, are really remarkable because, confirming what is shown by Factor 2 (Table 3(b)): they indicate for the first time the existence of (across-test) associations among variables from the OF and the ZM. (c) In this connection, a relative high number of OF crossings was associated with higher number of ZM entries (see Figure 1(c)), while also being a predictor of high $\mathrm{OF}$ rearings and low OF freezing levels (Figure 1(c); see also Figure 1(d) for the association between high OF rearings and low OF freezing). (d) Finally, in a similar manner as selection for extreme OF freezing led to differences in ZM entries (as shown in Figure 1(b)), the selection for extreme ZM entries predicts differences in $\mathrm{OF}$ freezing in the same direction (i.e. lower number of $\mathrm{ZM}$ entries are associated with higher levels of $\mathrm{OF}$ freezing; see Figure 1(e)).

Thus, according to the two different types of data analyses, i.e. the correlational-factorial approach and the analysis of differences between subgroups displaying extreme scores in representative variables, the results reveal some novel findings, notably that there exist associations among anxiety responses in the elevated zeromaze test and fearfulness-related responses in the openfield test in heterogeneous NIH-HS rats. To the best of our knowledge, these between-test associations are reported for the first time, and appear to be relevant for the concurrent validity of both tests. Freezing responses in the open-field test appear to be among the most powerful predictors of other OF responses (i.e. predicting differences in self-grooming and crossings) and, remarkably, OF freezing is also predictive of anxious behavior in the $\mathrm{ZM}$ (i.e. extremes in $\mathrm{OF}$ freezing predict differences in ZM "time" and "entries"). A paradoxical result was seen in a study using a very large sample of F2 rats (derived from the Roman rat strains), that showed a low positive correlation $(r=0.13, p<0.001)$ between time spent freezing during the initial 4-min period in a novel chamber (a shuttle-box apparatus, before two-way active avoidance training started) and distance run in the center of an OF [21]. On the contrary, and more in agreement with what could be expected, the same study showed moderate positive correlations among the above-mentioned novelty-induced freezing measure and context- and cueconditioned freezing/fear in a classical conditioning procedure $(\mathrm{r}=0.29$ and $\mathrm{r}=0.31$, respectively; both $\mathrm{p}<$ 0.001; [21]). These contrasting examples (of Aguilar et al. study) indicate that, even if the relationship between freezing in response to a novel environment and anxiety/ fearfulness measures obtained in other tests is hypothetically expected, it is poorly documented and/or still controversial. Present results represent, therefore, a confirmation that such a kind of inter-test relationship actually exists.

In the OF, it was found an interplay between freezing and SAP, at one hand, and crossings, rearings and grooming on the other hand (as suggest the sign of the respective variable loadings, see factor analysis in Table 3(b)). This interplay is in line with the notion that, once in contact with novel stimuli, the individual disengages from ongoing behavior, devotes attention to risk assessment and, if threat is ruled out, exploratory behavior takes place. Along this sequence, arousal rises at first and falls afterwards. This notion/sequence roughly corresponds to the concept of a behavioral inhibition system proposed by [19]. Thus, once placed in the OF, a rat is expected to at first show freezing and SAP (these behaviors are devoted to risk assessment) which, after some time, can be replaced by exploratory behaviors (for example: locomotion and rearing) and grooming (supposed to be related to 
dearousal, see below). Importantly, there can be great inter-individual variability in the time needed for the shift from a predominant inhibition-driven evaluation of the new situation to an active exploratory strategy.

The finding that grooming in the OF loaded negatively in an inhibition/disinhibition factor, together with locomotion and in opposition to freezing in the same test, is suited for considerations about its supposed relationship with dearousal. One can assume that inhibition and arousal go in parallel in an OF session. As far as grooming is more likely to take place after (or if) novelty-elicited inhibition has ceased, present data support a relationship between grooming and dearousal. Such a relationship has been suggested [26] based on works showing increased grooming when rodents are, for example, exposed to novelty [34], to unexpected stimuli [35], or to conditioned aversive context [36]. While the proposed relationship between grooming and dearousal has been and is still useful as a hypothesis, the role grooming exerts - if required for dearousal or only is an expression of that process - remains an open question (for an examination of this issue, see [37]).

The present results suggest that grooming would more likely be seen in individuals with relatively lowered inhibition (e.g. with low freezing in the open-field test; Figure 1(b)). More inhibited NIH-HS rats would instead devote their time to freeze and to risk assessment. Indeed, rats have been reported to show low levels of grooming when exposed to (relatively high) aversive situations (which produce relatively higher inhibition responses) such as a session in a highly illuminated open field [38], confinement to an open arm $[39,40]$ or during acquisition of the fear/anxiety-driven two-way active avoidance task [41].

Thus, at variance with what has been reported with regard to open field-induced grooming in F2 hybrid rats [21,22], or with the Roman rat strains [15,23-25], or with plus-maze [42] or illuminated box-induced grooming in Wistar rats [43], self-grooming in the present study represents (or goes in parallel to) behavioral disinhibition rather than anxiety or fear. Testing conditions and duration have been shown to be critical to allow fully expression of grooming responses, that in turn may have different conceptual (i.e. psychological) meanings as a function of different time points of novelty exposure or of different tasks or testing situations (see [37,40,44]). Moreover, the type of subjects used, as well as (even subtle) variations of conditions (within and) across laboratories, can also lead to relevant changes in phenotype profiles [9]. It remains possible that longer test duration (e.g. 10 or 15 minutes rather than 5 minutes) would allow the appearance of more grooming behaviour and/or different "dynamics" of grooming responses as a function of time (for discussion see [40]). If so, longer test duration could allow revealing different associations of grooming with other anxiety/fearfulness-related responses (and different conceptual meanings of grooming according to its dynamics), that are not detected with 5-min test sessions. Studies devoted to address some of these issues are currently under way.

Finally, the independence between the anxiety/conflict and inhibition/disinhibition factors found in the final factor analysis is remarkable, as well as the finding that these factors mainly correspond to the $\mathrm{ZM}$ and the OF tests, respectively. It is worth to mention that the ZM has been proposed and validated as a test for anxiety [4,5,8, $9,32,33]$ while the OF has long been used for evaluating anxiety/fearfulness as well as locomotor/exploratory activity [12-16,19-22]. Particular interest has the finding that extreme values of freezing in the open field test predict clear differences in ZM time and entries (into the open sections), and vice versa. Present results lend further support to the usefulness of these tests for the purposes they are commonly employed (i.e. anxiety, fearfulness) and add new evidence supporting their concurrent validity in heterogeneous rats, as indicated by the relationships observed among measures from both tests.

\section{ACKNOWLEDGMENTS}

C.E. was recipient of a postdoctoral fellowship from CNPq (201456/ 2011-7).

Supported by grants for the MICINN (PSI2009-10532), "Fundació La Maratò TV3” (ref. 092630/31), 2009SGR-0051 and the European project/consortium "EURATRANS” (grant agreement HEALTH-F42010-241504).

\section{REFERENCES}

[1] Hansen, C. and Spuhler, K. (1984) Development of the National Institutes of Health genetically heterogeneous stock. Alcoholism: Clinical and Experimental Research, 8, 477-479.

http://dx.doi.org/10.1111/j.1530-0277.1984.tb05706.x

[2] Spuhler, K. and Dietrich, R.A. (1984) Correlative analysis of ethanol-related phenotypes in rat inbred strains. Alcoholism: Clinical and Experimental Research, 8, 480484.

http://dx.doi.org/10.1111/j.1530-0277.1984.tb05707.x

[3] Baud, A., Hermsen, R., Guryev, V., Stridh, P., Graham, D., McBride, M.W., et al., (2013) Combined sequencebased and genetic mapping analysis of complex traits in outbred rats. Nature Genetics, 45, 767-775. http://dx.doi.org/10.1038/ng.2644

[4] Díaz-Morán, S., Mont-Cardona, C., Cañete, T., Blázquez, G., Martínez-Membrives, E., López-Aumatell, R., Tobeña, A. and Fernández-Teruel, A. (2012) Coping style and stress hormone responses in genetically heterogeneous rats: Comparison with the Roman rat strains. Behavioural Brain Research, 228, 203-210. 
http://dx.doi.org/10.1016/j.bbr.2011.12.002

[5] Díaz-Morán, S., Martínez-Membrives, E., López-Aumatell, R., Cañete, T., Blázquez, G., Palencia, M., Mont-Cardona, C., Estanislau, C., Tobeña, A. and Fernández-Teruel, A. (2013) What can we learn on rodent fearfulness/ anxiety from the genetically heterogeneous NIH-HS rat stock? Open Journal of Psychiatry, 3, 238-250. http://dx.doi.org/10.4236/ojpsych.2013.32022

[6] Johannesson, M., López-Aumatell, R., Stridh, P., Diez, M., Tuncel, J., Blázquez, G., et al. (2009) A resource for the simultaneous high-resolution mapping of multiple quantitative trait loci in rats: The NIH heterogeneous stock. Genome Research, 19, 150-158. http://dx.doi.org/10.1101/gr.081497.108

[7] López-Aumatell, R., Guitart-Masip, M., Vicens-Costa, E., Giménez-Llort, L., Valdar, W., Johannesson, M., Flint, J. Tobeña, A. and Fernandez-Teruel, A. (2008) Fearfulness in a large $\mathrm{N} / \mathrm{Nih}$ genetically heterogeneous rat stock: Differential profiles of timidity and defensive flight in males and females. Behavioural Brain Research, 188, 4155. http://dx.doi.org/10.1016/j.bbr.2007.10.015

[8] López-Aumatell, R., Vicens-Costa, E., Guitart-Masip, M., Martínez-Membrives, E., Valdar, W., Johannesson, M., Cañete, T., Blázquez, G., Driscoll, P., Flint, J., Tobeña, A. and Fernández-Teruel, A. (2009) Unlearned anxiety predicts learned fear: A comparison among heterogeneous rats and the Roman rat strains. Behavioural Brain Research, 202, 92-101.

http://dx.doi.org/10.1016/j.bbr.2009.03.024

[9] López-Aumatell, R., Martínez-Membrives, E., Vicens- Costa, E., Cañete, T., Blázquez, G., Mont-Cardona, C., Johannesson, M., Flint, J., Tobeña A. and Fernández-Teruel, A. (2011) Effects of environmental and physiological covariates on sex differences in unconditioned and conditioned anxiety and fear in a large sample of genetically heterogeneous (N/Nih-HS) rats. Behavioral and Brain Functions, 7, 48.

http://dx.doi.org/10.1186/1744-9081-7-48

[10] Palència, M., Díaz-Morán, S., Mont-Cardona, C., Cañete, T., Blázquez, G., Martínez-Membrives, E., López-Aumatell, R., Tobeña, A. and Fernández-Teruel, A. (2013) Helplessness-like escape deficits of NIH-HS rats predict passive behavior in the forced swimming test: Relevance for the concurrent validity of rat models of depression. World Journal of Neuroscience, 3, 83-92. http://dx.doi.org/10.4236/wjns.2013.32012

[11] Vicens-Costa, E., Martínez-Membrives, E., López-Aumatell, R., Guitart-Masip, M., Cañete, T., Blázquez, G., Tobeña, A. and Fernández-Teruel, A. (2011) Two-way avoidance acquisition is negatively related to conditioned freezing and positively associated with startle reactions: A dissection of anxiety and fear in genetically heterogeneous rats. Physiology \& Behavior, 103, 148-156. http://dx.doi.org/10.1016/j.physbeh.2010.12.009

[12] Broadhurst, P.L. (1957) Determinants of emotionality in the rat. I. Situational factors. British Journal of Psychology, 48, 1-12.

http://dx.doi.org/10.1111/j.2044-8295.1957.tb00594.x
[13] Broadhurst, P.L. (1958) Determinants of emotionality in the rat. II. Antecedent factors. British Journal of Psychology, 49, 12-20. http://dx.doi.org/10.1111/j.2044-8295.1958.tb00632.x

[14] Broadhurst, P.L. (1975) The Maudsley reactive and non reactive strains of rats: A survey. Behavior Genetics, 5, 299-319. http://dx.doi.org/10.1007/BF01073201

[15] Escorihuela, R.M., Fernández-Teruel, A., Gil, L., Aguilar, R., Tobeña, A. and Driscoll, P. (1999) Inbred Roman high- and low-avoidance rats: Differences in anxiety, novelty-seeking, and shuttlebox behaviors. Physiology \& Behavior, 67, 19-26. http://dx.doi.org/10.1016/S0031-9384(99)00064-5

[16] Escorihuela, R.M. and Fernández-Teruel, A. (1998) Modelos animales en psicopatologia y psicofarmacologia: Del análisis experimental de la conducta a la neurogenética. Psicología conductista, 6, 165-191.

[17] Fernandez-Teruel, A., Escorihuela, R.M., Nuñez, J.F., Gomá, M., Driscoll, P. and Tobeña, A. (1992) Early stimulation effects on novelty-induced behavior in two psychogenetically-selected rat lines with divergent emotionality profiles. Neuroscience Letters, 137, 185-188. http://dx.doi.org/10.1016/0304-3940(92)90400-2

[18] Gray, J.A. and Lalljee, B. (1974) Sex differences in emotional behavior in the rat: Correlation between open field defecation and active avoidance. Animal Behaviour, 22, 856-861. http://dx.doi.org/10.1016/0003-3472(74)90008-6

[19] Gray, J.A. and McNaughton, N. (2000) The neuropsychology of anxiety: An enquiry into the functions of the septo-hippocampal system. Oxford University Press, Oxford.

[20] Levine, S. and Broadhurst, P.L. (1963) Genetic and ontogenetic determinants of adult behavior in the rat. Journal of Comparative and Physiological Psychology, 56, 423-428. http://dx.doi.org/10.1037/h0040285

[21] [Aguilar, R., Gil, L., Flint, J., Gray, J.A., Dawson, G.R., Driscoll, P., et al., (2002) Learned fear, emotional reactivity and fear of heights: A factor analytic map from a large F2 intercross of Roman rat strains. Brain Research Bulletin, 57, 17-26.

[22] Aguilar, R., Gil, L., Gray, J.A., Driscoll, P., Flint, J., Dawson, G.R., Giménez-Llort, L., Escorihuela, R.M., Fernández-Teruel, A. and Tobeña, A. (2003) Fearfulness and sex in F2 Roman rats: Males display more fear though both sexes share the same fearfulness traits. Physiology \& Behavior, 78, 723-732. http://dx.doi.org/10.1016/S0031-9384(03)00043-X

[23] Steimer, T. and Driscoll, P. (2003) Divergent stress responses and coping styles in psychogenetically selected Roman high-(RHA) and low-(RLA) avoidance rats: behavioral, neuroendocrine and developmental aspects. Stress, 6, 87-100. http://dx.doi.org/10.1080/1025389031000111320

[24] Steimer, T., Escorihuela, R.M., Fernández-Teruel, A. and Driscoll, P. (1998) Long-term behavioural and neuroendocrine changes in Roman high-(RHA/Verh) and low(RLA-Verh) avoidance rats following neonatal handling. 
International Journal of Developmental Neuroscience, 16, 165-174.

http://dx.doi.org/10.1016/S0736-5748(98)00032-X

[25] Ferré, P., Fernández-Teruel, A., Escorihuela, R.M., Driscoll, P., Corda, M.G., Giorgi, O. and Tobeña, A. (1995) Behavior of the Roman/Verh high- and low-avoidance rat lines in anxiety tests: Relationship with defecation and self-grooming. Physiology \& Behavior, 58, 1209-1213. http://dx.doi.org/10.1016/0031-9384(95)02068-3

[26] Spruijt, B.M., van Hooff, J.M. and Gispen, W.H. (1992) The ethology and neurobiology of grooming behavior. Physiological Reviews, 72, 825-852.

[27] Giorgi, O., Lecca, D., Piras, G., Driscoll, P. and Corda, M.G. (2003) Dissociation between mesocortical dopamine release and fear-related behaviours in two psychogenetically selected lines of rats that differ in coping strategies to aversive conditions. European Journal of Neuroscience, 17, 2716-2726. http://dx.doi.org/10.1046/j.1460-9568.2003.02689.x

[28] Cruz, A.P.M., Frei, F. and Graeff, F.G. (1994) Ethopharmacological analysis of rat behavior on the elevated plus-maze. Pharmacology Biochemistry and Behavior, 49, 171-176. http://dx.doi.org/10.1016/0091-3057(94)90472-3

[29] Anseloni, V.Z. and Brandão, M.L. (1997) Ethopharmacological analysis of behaviour of rats using variations of the elevated plus-maze. Behavioural Pharmacology, 8, 533-540. http://dx.doi.org/10.1097/00008877-199711000-00011

[30] Prut, L. and Belzung, C. (2003) The open field as a paradigm to measure the effects of drugs on anxiety-like behaviors: A review. European Journal of Pharmacology, 463, 3-33.

http://dx.doi.org/10.1016/S0014-2999(03)01272-X

[31] Guitart-Masip, M., Giménez-Llort, L., Fernández-Teruel, A., Cañete, T., Tobeña, A., Ogren, S.O., Terenius, L. and Johansson, B. (2006) Reduced ethanol response in the alcohol-preferring RHA rats and neuropeptide mRNAs in relevant structures. European Journal of Neuroscience, 23, 531-540.

http://dx.doi.org/10.1016/S0014-2999(03)01272-X

[32] Pähkla, R., Kask, A. and Rägo, L. (2000) Differential effects of beta-carbolines and antidepressants on rat exploratory activity in the elevated zero-maze. Pharmacology Biochemistry and Behavior, 65, 737-742. http://dx.doi.org/10.1016/S0091-3057(99)00265-8

[33] Shepherd, J,K., Grewal, S.S., Fletcher, A., Bill, D.J. and Dourish, C.T. (1994) Behavioural and pharmacological characterisation of the elevated "zero-maze" as an animal model of anxiety. Psychopharmacol, 116, 56-64. http://dx.doi.org/10.1007/BF02244871

[34] Bindra, D. and Spinner, N. (1958) Response to different degrees of novelty: The incidence of various activities. Journal of the Experimental Analysis of Behavior, 1, 341350. http://dx.doi.org/10.1901/jeab.1958.1-341
[35] Fentress, J.C. (1968) Interrupted ongoing behavior in two species of vole (Microtus agrestis and Clethrionomys brittannicus) I: Response as a function of preceeding activity and the context of apparently irrelevant motor patterns. Animal Behaviour, 16, 135-153. http://dx.doi.org/10.1016/0003-3472(68)90124-3

[36] Hannigan, J.H. and Issacson, R.L. (1981) Conditioned excessive grooming in the rat after footshock: Effect of naloxone and situational cues. Behavioral and Neural Biology, 33, 280-292. http://dx.doi.org/10.1016/S0163-1047(81)92045-8

[37] Van Erp, A.M.M., Kruk, M.R., Meelis, W. and WillekensBramer, D.C. (1994) Effect of environmental stressors on time course, variability and form of self-grooming in the rat: Handling, social contact, defeat, novelty, restraint and fur moistening. Behavioural Brain Research, 65, 47-55. http://dx.doi.org/10.1016/0166-4328(94)90072-8

[38] Bouwknecht, J.A., Spiga, F., Staub, D.R., Hale, M.W., Shekhar, A. and Lowry, C.A. (2007) Differential effects of exposure to low-light or high-light open-field on anxiety-related behaviors: Relationship to c-Fos expression in serotonergic and non-serotonergic neurons in the dorsal raphe nucleus. Brain Research Bulletin, 72, 32-43. http://dx.doi.org/10.1016/j.brainresbull.2006.12.009

[39] Mairesse, J., Viltart, O., Salome, N., Giuliani, A., Catalani, A., Casolini, P., et al. (2007) Prenatal stress alters the negative correlation between neuronal activation in limbic regions and behavioral responses in rats exposed to high and low anxiogenic environments. Psychoneuroendocrinology, 32, 765-776. http://dx.doi.org/10.1016/j.psyneuen.2007.03.013

[40] Estanislau, C. (2012) Cues to the usefulness of grooming behavior in the evaluation of anxiety in the elevated plus-maze. Psychology \& Neuroscience, 5, 105-112. http://dx.doi.org/10.3922/j.psns.2012.1.14

[41] Estanislau, C., Díaz-Morán, S., Cañete, T., Blázquez, G., Tobeña, A. and Fernández-Teruel, A. (2013) Contextdependent differences in grooming behavior among the NIH heterogeneous stock and the Roman high- and lowavoidance rats. Neuroscience Research, 77, 187-201. http://dx.doi.org/10.1016/j.neures.2013.09.012

[42] Estanislau, C., Ramos, A.C., Ferraresi, P.D., Costa, N.F., de Carvalho, H.M.C.P. and Batistela, S. (2011) Individual differences in the elevated plus-maze and the forced swim test. Behavioural Processes, 86, 46-51. http://dx.doi.org/10.1016/j.beproc.2010.08.008

[43] Kalueff, A.V. and Tuohimaa, P. (2005) The grooming analysis algorithm discriminates between different levels of anxiety in rats: Potential utility for neurobehavioural stress research. Journal of Neuroscience Methods, 143, 169-177. http://dx.doi.org/10.1016/j.jneumeth.2004.10.001

[44] Komorowska, J. and Pisula, W. (2003) Does changing levels of stress affect the characteristics of grooming behavior in rats? International Journal of Comparative Psychology, 16, 237-246. 